\title{
CT Urography
}

National Cancer Institute

\section{Source}

National Cancer Institute. CT Urography. NCI Thesaurus. Code C159883.

The use of computed tomography to image the kidney and urinary system. 